\title{
Model Pengaturan Suhu Kelembaban Otomatis Pada Kumbung Jamur Tiram
}

\author{
Ananto \\ Program Studi Agroteknologi Sekolah Tinggi Ilmu Pertanian (Stiper) Sawahlunto Sijunjung \\ Email: rakha_jamur@yahoo.com
}

\begin{abstract}
ABSTRAK
Budidaya jamur tiram pada area yang memiliki suhu tinggi memerlukan teknik perawatan secara khusus. Perkembangan teknologi sekarang ini memudahkan dalam melakukan perawatan budidaya jamur tiram. Bahkan sudah tidak sedikit yang bisa mengatur suhu dan kelembapan secara otomatis di dalam ruangan budidaya. Penelitian ini bertujuan untuk mengetahui sistem pengatur suhu otomatis yang dapat memudahkan perawatan dan mengeliminir kegagalan produksi jamur tiram. Namun pengaturan suhu kelembaban tidaklah cukup sempurna kalau tidak ada model dan teknik pengaturannya. Model yang akan dibuat dengan cara menggunakan teknik Digital Skylite yang dihubungkan dengan sumber arus, Digital skylite ini berfungsi sebagai timer otomatis. Tujuan Dari Penelitian Ini Adalah Untuk Mendapatkan Model Rancangan Alat Yang tepat dengan menggunakan Digital Skylite dan untuk melihat lama waktu yang tepat dalam pengaturan Digital Skylite. Metode yang digunakan dalam pengambilan data penelitian ini adalah Pengamatan secara Langsung (observasi), Observasi dilakukan dengan meneliti dan mengadakan pengamatan terhadap obyek yang diteliti secara langsung. Hasil dari penelitian adalah mendapatkan model rancangan pengaturan suhu yang maksimal.
\end{abstract}

Kata kunci : jamur tiram, Digital Skylite, suhu kelembaban

\begin{abstract}
Oyster mushroom cultivation in areas that have high temperatures requires special maintenance techniques. The development of technology now makes it easy to carry out maintenance treatments for oyster mushrooms. Not even a few can regulate temperature and humidity automatically during the cultivation which is an automatic temperature. The regulator can facilitate maintenance and minimize the failure of oyster mushroom production. However, the humidity temperature setting is not perfect enough if there have no models and adjusting techniques. The model will be set by Digital Skylite which was connecting to the current source, Digital Skylite functions as an automatic timer. The purpose of this research was to get the right tool design model using Digital Skylite and to see the correct length of time in the Digital Skylite settings. The method used in data collection in this study using Direct Observation (Observation), Observations were carried out by examining and observing the object under observation directly. The results of the study were to obtain a maximum temperature regulation design model.
\end{abstract}

Keywords: oyster mushroom, Digital Skylite, humidity temperature

\section{PENDAHULUAN}

Jamur Tiram biasanya tumbuh di hutan, pada kayu-kayuan. Seiring berkembangnya zaman, kini jamur tiram sudah di budidayakan dirumahrumah biasa di sebut kumbung. Kumbung adalah bangunan tempat 
kegiatan budidaya jamur tiram. Tahap awal dalam budidaya jamur tiram adalah menyiapkan kumbung dan membuat rak-rak tempat penyimpanan baglog. Sebuah bangunan kumbung harus memiliki kemampuan untuk menjaga suhu dan kelembaban. Rakrak dibuat bersusun secara vertikal untuk memaksimalkan ruangan agar dapat menyimpan baglog lebih banyak. Jarak ketinggian ruang antar rak minimal $40 \mathrm{~cm}$. Rak dapat dibuat 4-5 tingkat atau disesuaikan dengan lebar $40 \mathrm{~cm}$. Rak dibuat memanjang membentuk lorong dengan panjang sesuai panjang bangunan kumbung. Jarak antar rak minimal $80 \mathrm{~cm}$ agar mudah dalam merawat. (Prawirahardja, 2010)

Secara topografi Kabupaten Sijunjung memiliki potensi untuk pengembangan jamur tiram (Pleurotus ostreatus). Petani jamur tiram di kabupaten sijunjung masih tergolong sedikit hal ini disebabkan karena petani jamur tiram setelah membudidayakan jamur ternyata banyak mengalami kendala. Saat ini bukan hanya sekedar bagaimana cara membudidayakan jamur saja yang menjadi fokus utama para pelaku usaha, hal yang paling penting untuk diperhatikan yaitu bagaimana merawat jamur agar panen yang dihasilkan memiliki kualitas yang baik, terutama kualitas kumbung jamur tersebut. (Ananto, 2017)

Budidaya jamur tiram di daerah dataran tinggi yang memiliki suhu yang dingin itu sudah biasa dan sangat mudah untuk mengatur/merawatnya, sedangkan pada daerah dataran rendah budidayakan jamur tiram perlu pengaturan suhu dan kelembaban yang sangat ekstra. Untuk di daerah panas pengaturan suhu dan kelembaban ruangan penumbuhan jamur tiram diperlukan suhu antara $22{ }^{0} \mathrm{C}-28{ }^{0} \mathrm{C}$ sedangkan kelembaban 80-90 \%. Agar pertumbuhan jamur dalam kumbung dapat optimal maka suhu dan kelembaban dari pada kumbung harus dijaga sesuai dengan kondisi alaminya. Di dataran rendah, pengaturan suhu dan kelembaban kumbung jamur masih dilakukan secara manual, yaitu dengan cara hanya menyemprotkan butiran butiran air. (Widodo et al., 2013)

Cara tersebut kurang menjamin kesesuaian kelembaban yang dibutuhkan, selain itu suhu kumbung belum diatur karena masih mengandalkan suhu lingkungan sekitar. Dengan demikian apabila suhu lingkungan tidak sesuai dengan suhu yang dibutuhkan jamur tiram, produksi jamur akan menurun. untuk memaksimalkan pertumbuhan jamur kondisi suhu dan kelembaban perlu diperhatikan, sehingga keadaan suhu dan kelembaban sesuai kebutuhan pertumbuhan jamur. Salah satu cara menjaga suhu dan kelembaban kumbung adalah dengan cara membuat model dan pengaturan yang tepat bisa menjaga kondisi kumbung yang ideal yaitu ruang budidaya memiliki suhu sekitar $22-28{ }^{0} \mathrm{C}$ dan kelembaban relatif (RH) $80 \%-90 \%$. Menurut Anggi $+28{ }^{0} \mathrm{C}$, penelitian yang dilakukan dengan menggunakan sensor suhu, hasil yang dapatkan dari selisih suhu rata-rata sensor Digital 
Humidity and Temperature (DHT) 11 sebesar $1,78 \quad{ }^{0} \mathrm{C}$ dan selisih kelembapan rata-rata 4,8 \% dengan menggunakan pembanding dari termometer digital. (Anggi et al., 2016)

Menurut, (Ajie Putranto dan Mad Yamin, 2011). Pada penelitian yang dilakukan pada karung goni digunakan sebagai media pendingin ruang budidaya jamur dan pembasahannya dilakukan secara otomatis menggunakan pewaktu setiap 15 menit. Setelah beberapa waktu pembasahan, terjadi perbedaan nyata pada suhu ruang dengan karung goni basah dan suhu ruang tanpa karung goni basah. Namun, kelembaban relativenya tidak berbeda nyata. Hasil panen jamur pada 75 baglog pada kondisi ruang yang didinginkan dengan karung goni basah adalah $23.5 \mathrm{~kg}$, sementara yang tidak didinginkan hasilnya $16.7 \mathrm{~kg}$.

Selama ini belum ada kajian terkait model dan pengaturan suhu untuk meningkatkan produksi jamur tiram, hanya sebatas budidaya saja. Dengan demikian diperlukan penelitian tentang pembuatan model dan teknik pengaturan suhu secara otomatis dengan menggunakan Digital Skylite dalam memperbaiki permasalahan suhu yang selama ini membuat resah petani jamur tiram sehingga nantinya dapat menghasilkan jamur tiram yang baik. (Abdullah et al., 2012).

\section{Tujuan penelitian}

$\begin{array}{crr} & \text { Tujuan Penelitian Ini } & \text { Adalah } \\ \text { Untuk } & \text { Mendapatkan } & \text { Model }\end{array}$

Rancangan Yang tepat pada kumbung jamur tiram

\section{METODE PENELITIAN}

\section{Tahapan penelitian}

Penelitian pendahuluan dilakukan yaitu untuk membuat rangkaian model jaringan pipa air dan pengaturan suhu ruangan.

\section{Tahapan Penelitian}

1. Pembuatan kumbung jamur tiram Pembuatan kumbung dimaksudkan untuk memastikan ukuran kumbung sesuai dengan ukuran jarak nozel yang akan di rancang.

2. Pembuatan rak-rak baglog Rak-rak baglog di buat menggunakan kayu yang kuat dan tahan terhadap percikan air hujan, Karena air yang keluar dari nozel sama seperti air hujan.

3. Membuat rangkaian model jaringan pipa air dalam pengaturan suhu ruangan.

\section{Lokasi dan waktu penelitian}

Penelitian ini dilakukan di kelompok tani Jamur Jaya yang berada di lingkungan STIPER sawahlunto sijunjung, pelaksanaan penelitian berlangsung lebih kurang 6 bulan (Mei s/d Oktober 2019 ).

\section{HASIL DAN PEMBAHASAN}

\section{Pembuatan kumbung jamur tiram}

Sebelum pembuatan kumbung terlebih dahulu kita tentukan ukuran kumbung tersebut. Adapun langkah-langkahnya sebagai berikut : 
1) menentukan Ukuran kumbung

Secara umum ukuran kumbung yang ideal, yaitu lebar $4 \mathrm{~m}$, panjang $6 \mathrm{~m}$, dan tinggi $2,5 \mathrm{~m}$. didalam penelitian ini ukuran kumbung di buat $8 \mathrm{~m} \times 14 \mathrm{~m}$ dengan tinggi kumbung 3,5 m. Di dalam kumbung dibuat petak untuk membangun rak tempat menaruh baglog jamur. Jarak antar petak sekitar $80 \mathrm{~cm}$. (Gemalasari. 2002)
2) Bagian-bagian kumbung

Dinding kumbung jamur terbuat dari papan, atapnya terbuat dari seng, lantai permukaan dilapisi dengan pasir, sedangkan pada dinding kita buat jendela dengan tujuan supaya sirkulasi udara tetap lancar.

Model pengaturan suhu yang telah dibuat dapat dilihat pada gambar dibawah ini :

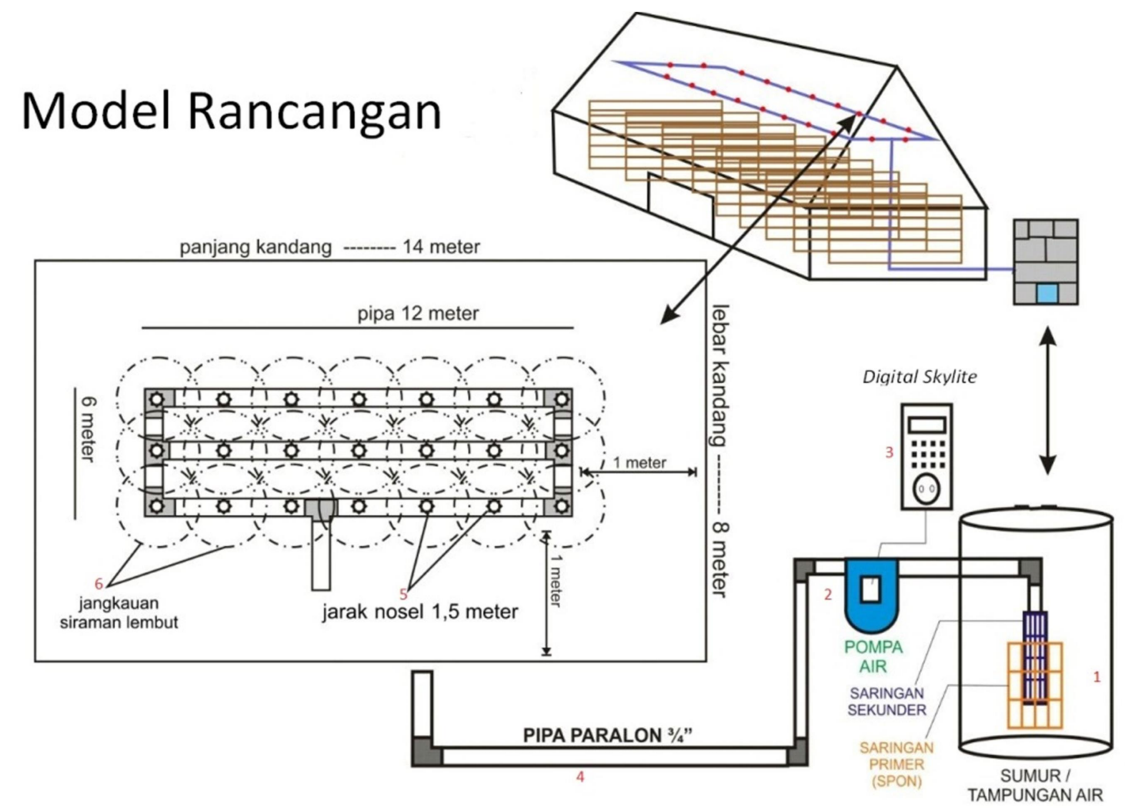

Keterangan gambar 2 :

Panjang kumbung $\quad: 14 \mathrm{~m}$

Lebar kumbung $\quad: 8 \mathrm{~m}$

Tinggi kumbung $\quad: 4 \mathrm{~m}$

Dari gambar diatas, sistem kerjanya yaitu pertama sekali mempersiapkan air, lalu menghubungkan mesin pompa air dengan sumber arus kemudian mempersiapkan atau mengatur Digital Skylite sesuai dengan kebutuhan waktunya, misalkan kita atur selama 3 menit. Secara otomatis mesin pompa air tersebut akan mati secara sendiri dalam waktu 3 menit. Air yang masuk ke pipapipa akan didorongkan menuju nozel-nozel yang sudah diatur sedemikian dengan jarak nozel 1,5 m, karena dengan jangkauan 1,5 m tersebut, air sudah bisa mencapai pada titik terjauh dari pinggir dinding kumbung

\section{KESIMPULAN}

Berdasarkan penelitian yang telah dilakukan, dapat ambil kesimpulan model rancangan yang di dapatkan yaitu model jaringan sederhana dengan jarak antar nozel 1,5 $\mathrm{m}$ serta jarak baglog dengan nozel sejauh $50 \mathrm{~cm}$. 


\section{DAFTAR PUSTAKA}

Ajie Putranto dan Mad yamin. 2011. Pengendalian Suhu Ruang pada Budidaya Jamur Tiram dengan Karung Goni Basah. Jurnal keteknikan pertanian.

Abdullah, S. Hardhienata, and A. Chairunnas, 2012. "Model Pengaturan Suhu Dan Kelembaban Pada Ruang Jamur Tiram Menggunakan Sensor Dht11 DanMikrokontroler," J. Artic., vol. 2,

Ananto, syaifuddin Islami, 2017. Provision of Organik Herbs as a perancer of growing pinhead oyster mushroom. Prosiding seminar Nasional. Politeknik Payakumbuh.

Anggi Triyanto dan Nurwijayanti K. N. 2016. Pengatur Suhu dan Kelembapan otomatis Pada Budidaya Jamur Tiram Menggunakan Mikrokontroler ATMega16. Jurnal TESLA VOL. 18/NO. 1.

Prawirahardja. 2010. "Cara Budidaya Jamur

Tiram". tabloidgallery.wordpres s.com.Diakses tanggal 8 Januari 2011.

Gemalasari. 2002. Pengendalian Kumbang Cyllodes bifacies Walker (Coleoptera Nitidulidae) Pada Jamur Tiram Putih Dengan Pemasangan Barier. Fakultas Pertanian. Institut Pertanian Bogor. Skripsi.

Widodo, C. S. Prabowo, S. Winanti, and R. E. Juwanto, 2013 ."Rancang Bangun Sistem Penyiraman Tiram Secara Otomatis Menggunakan Sensor Suhu Berbasis Mikrokontroler
Atmega8," J. Ris. Drh. 2013, pp. 31-40, 